\title{
Correlation of postoperative magnetic resonance image measurements with persisting acetabular dysplasia in open reduction of developmental hip dysplasia
}

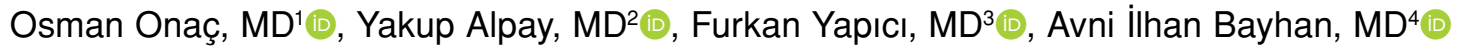 \\ ${ }^{1}$ Department of Orthopedics and Traumatology, Tatvan State Hospital, Tatvan, Turkey \\ 2Department of Orthopedics and Traumatology, Sultanbeyli State Hospital, Istanbul, Turkey \\ ${ }^{3}$ Department of Orthopedics and Traumatology, Erzincan University Faculty of Medicine, Erzincan, Turkey \\ ${ }^{4}$ Department of Orthopedics and Traumatology, Health Science University, Baltalimani Bone Diseases Training and Research \\ Hospital, Istanbul, Turkey
}

Developmental dysplasia of the hip (DDH) is a common disorder that requires early treatment by orthosis or open or closed reduction. ${ }^{[1-4]}$ If left untreated, it causes an abnormal gait pattern, lifelong disability, and hip osteoarthritis in early adulthood. ${ }^{[5-8]}$ The disease spectrum ranges from acetabular dysplasia or subluxation to dislocation. ${ }^{[9]}$ After hip reduction, acetabular dysplasia may persist, and these patients would need further surgery. Ultrasonography (USG) is the gold standard for the evaluation of the concentric reduction of the hip within the first six months, ${ }^{[10]}$ as it is difficult to evaluate the reduction by X-ray as the femoral head is not yet ossified..$^{[9]}$

Received: March 08, 2021

Accepted: May 27, 2021

Published online: June 11, 2021

Correspondence: Yakup Alpay, MD. Sultanbeyli Devlet Hastanesi Ortopedi ve Travmatoloji Kliniği, 34935 Sultanbeyli, istanbul, Türkiye.

E-mail: yakupalpayy@hotmail.com

Doi: $10.52312 /$ jdrs.2021.48

Citation: Onaç O, Alpay Y, Yapıcı F, Bayhan Ai. Correlation of postoperative magnetic resonance image measurements with persisting acetabular dysplasia in open reduction of developmental hip dysplasia. Jt Dis Relat Surg 2021;32(2):461-467.

(O2021 All right reserved by the Turkish Joint Diseases Foundation

This is an open access article under the terms of the Creative Commons Attribution-NonCommercial License, which permits use, distribution and reproduction in any medium, provided the original work is properly cited and is not used for commercial purposes (http://creativecommons.org/licenses/by-nc/4.0/)

\section{ABSTRACT}

Objectives: The aim of this study was to evaluate correlation of post-reduction magnetic resonance imaging (MRI)-based parameters with residual acetabular dysplasia in developmental dysplasia of the hip (DDH) patients who underwent open reduction.

Patients and methods: A total of 62 hips of 54 children $(5$ males, 57 females; mean age: $8.5 \pm 3.5$ months; range, 0 to 24 months) with a diagnosis of DDH who underwent open reduction between January 2012 and January 2017 were retrospectively analyzed. The acetabular head index (AHI), head coverage index (HCI), sphericity, bony acetabular index (BAI), cartilage acetabular index (CAI), anterior acetabular index (AAI), posterior acetabular index (PAI), abduction angle (AA), and acetabular medial wall thickness were measured by MRI. The correlation between MRI measurements and residual acetabular dysplasia was evaluated.

Results: The mean follow-up was $23.7 \pm 10.1$ (range, 12 to 56 ) months. The mean age at the final examination was $47.6 \pm 10.4$ months. The age at the time of operation $(\mathrm{r}=0.250, \mathrm{p}=0.049)$, medial wall thickness $(r=0.304, p=0.016)$, AAI $(r=0.729, p<0.001)$, PAI $(r=0.590, p<0.001)$, and early postoperative AI $(r=0.900, p<0.001)$ at the third postoperative month were positively correlated with the last follow-up AI. The AHI $(r=-0.512, p<0.001)$, sphericity $(\mathrm{r}=-0,661, \mathrm{p}<0.001)$, and HCI $(\mathrm{r}=-0.554, \mathrm{p}<0.001)$ were negatively correlated with the last follow-up AI.

Conclusion: Post-reduction MRI parameters can be used to evaluate correlation with persistent acetabular dysplasia in DDH patients.

Keywords: Acetabular dysplasia, hip dysplasia, magnetic resonance imaging, open reduction.

Assessment of a hip reduction after a surgical intervention is technically difficult. ${ }^{[11]}$ Either USG or $X$-ray cannot be used after closed or open reduction due to spica casting. The concentric reduction of the hip can be evaluated easily and reliably by computed 
tomography (CT) after open reduction; however, it has the disadvantage of radiation exposure. ${ }^{[12]}$ Recently, magnetic resonance imaging (MRI) has been used to assess hip reduction to avoid radiation exposure. ${ }^{[13]}$ Chin et al. ${ }^{[12]}$ concluded that MRI was an effective alternative to $\mathrm{CT}$ imaging with excellent sensitivity and specificity. Other previous reports described MRI measurements as useful for the evaluation of postoperative hip reduction. ${ }^{[14,15]}$

In the present study, we hypothesized that medial wall thickness had an association with residual acetabular dysplasia. We, therefore, aimed to evaluate the correlation between post-reduction MRI-based parameters and persisting acetabular dysplasia in DDH patients who underwent open reduction.

\section{PATIENTS AND METHODS}

This single-center, retrospective study was conducted at Baltalimani Bone Diseases Training and Research Hospital, Department of Orthopedics and Traumatology, between January 2012 and January 2017. The medical records of the patients who were diagnosed with DDH using the International Classification of Diseases, $10^{\text {th }}$ Revision codes were reviewed. Inclusion criteria were undergoing open reduction for $\mathrm{DDH}$ and casting at the age of 3 to 12 months. Exclusion criteria were as follows: a follow-up period of less than one year $(n=2)$, absence of MRI evaluation on the first postoperative day $(n=12)$, low-quality MRI scans on which measurements could not be performed $(n=28)$, having neurological disorder or teratologic hips $(n=14)$, and age less than two years $(n=9)$. Of a total of 119 hips, 62 in 54 children (5 males, 57 females; mean age: $8.5 \pm 3.5$ months; range, 0 to 24 months) that fulfilled the inclusion criteria were included in the study. A written informed consent was obtained from the parents and/or legal guardians of the patients before surgery. The study protocol was approved by the Health Science University, Baltalimani Bone Diseases Training and Research Hospital Review Board (09.11.2017/17). The study was conducted in accordance with the principles of the Declaration of Helsinki.

The operations were performed by four different surgeons in a single center. The medial open approach was used in all patients. The MRI scans were obtained using a 1.5 T Signa Scanner (General Electric Healthcare, WI, USA). T2-weighted turbo spin-echo hip images were used for evaluation. The MRI scans had a 3-mm slice thickness. All measurements were made using annotation tools on a light picture archiving and communications system workstation (Koninklijke Philips Electronics, Eindhoven, The Netherlands). The measurements were performed by a pediatric orthopedic surgeon with five years of experience who was blinded to the study design.

On the first postoperative day, the acetabular head index (AHI), head coverage index (HCI), and sphericity were measured, as previously described. ${ }^{[14,16]}$ The bony acetabular index (BAI) and cartilage acetabular index (CAI) were measured, as described by Huber et al. ${ }^{[17]}$ The anterior acetabular index (AAI), posterior acetabular index (PAI), and abduction angle (AA) were measured on axial images. ${ }^{[13]}$ The reliability of the indices measured on infant hip MRI scans was previously evaluated. ${ }^{[14,16-18]}$

For the measurement of the acetabular medial wall thickness (AMWT), the section in which the femoral head is widest in the axial plane, on the T2 pelvis MRI image, was used. The distance between the deepest point where the femoral head touches the acetabulum and the medial wall of the acetabulum was measured (Figure 1). Two separate observers who were blinded the study measured the AMWT twice.

Tönnis ${ }^{[19]}$ first described the limits of the acetabular index (AI) as normal, mildly dysplastic, or severely dysplastic. The AI was measured on the day of operation, after the spica removal at the third month after surgery (early postoperative $\mathrm{AI}$ ), and at the last follow-up on X-ray images. According to the last follow-up AI, the hips were divided into three

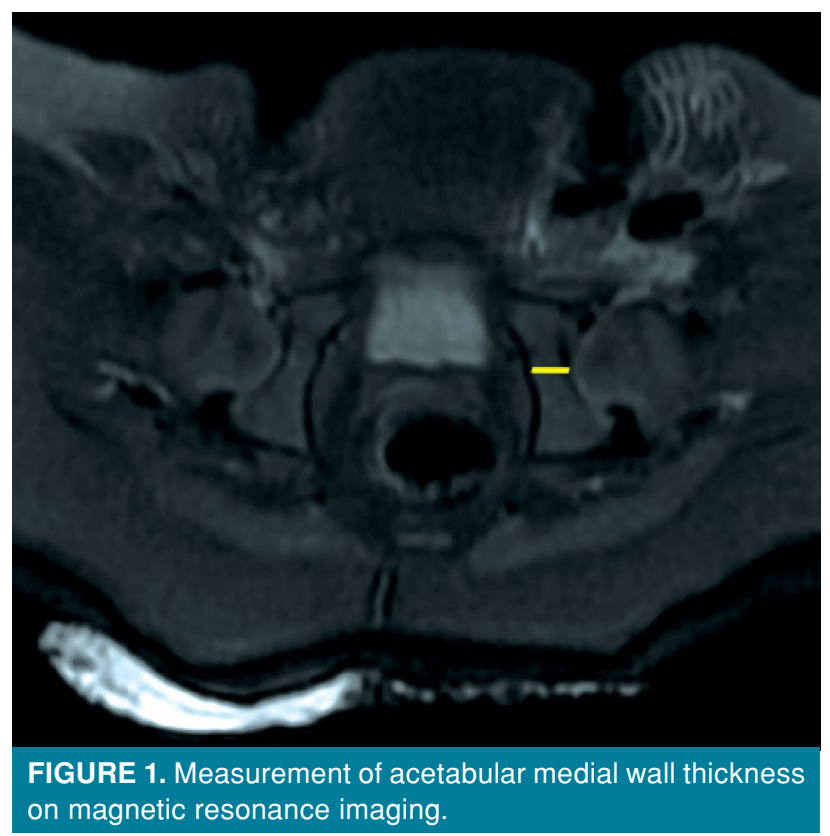


groups, as described. ${ }^{[19]}$ The correlation between the last follow-up AI and MRI parameters measured on the day after the operation was evaluated.

\section{Surgical technique}

The Ludloff approach was used in medial open reduction. ${ }^{[1]}$ After a 4 -cm incision was made from the groin, adductor longus tenotomy was performed. It was deepened between the adductor brevis and pectineus muscles. Iliopsoas tenotomy was performed. Following capsule incision, ligamentum teres and pulvinar excision were performed. The transverse acetabular ligament was cut to achieve concentric reduction. After checking the hip stability, the skin was closed without suturing the capsule. After the procedure, a well-molded cast was applied at 90 to $100^{\circ}$ of hip flexion.

\section{Statistical analysis}

Statistical analysis was performed using the IBM SPSS version 22.0 software (IBM Corp., Armonk, NY, USA). Descriptive data were expressed in mean \pm standard deviation (SD), median (min-max) or number and frequency. The Kolmogorov-Smirnov test was used to measure the distribution of the variables. In the analysis of independent quantitative data, the Kruskal-Wallis and Mann-Whitney U tests were used. The Wilcoxon test was used to analyze dependent quantitative data. In the analysis of independent qualitative data, the chi-square test and Fisher exact test were used, when the chi-square test conditions were not met. The Spearman correlation analysis was used to examine the relation of MRI measurements with residual acetabular dysplasia. A $p$ value of $<0.05$ was considered statistically significant.

\section{RESULTS}

At the final follow-up, 23 hips (37\%) had a normal AI, $19(30.6 \%)$ had mild dysplasia, and the remaining 20 hips (32.4\%) had severe dysplasia. The mean operation age was $8.5 \pm 3.5$ (range, 3 to 16) months, and the mean follow-up was $23.7 \pm 10.1$ (range, 12 to 56)

\begin{tabular}{|c|c|c|c|c|c|}
\hline \multicolumn{6}{|c|}{$\begin{array}{l}\text { TABLE I } \\
\text { s of the patients }\end{array}$} \\
\hline Patient demographics & $\mathrm{n}$ & $\%$ & Mean $\pm S D$ & Median & Min-Max \\
\hline Operation age (month) & & & $8.5 \pm 3.5$ & 8.0 & $3.0-16.0$ \\
\hline Follow-up time (month) & & & $23.7 \pm 10.1$ & 23.5 & $12.0-56.0$ \\
\hline \multicolumn{6}{|l|}{ Sex } \\
\hline Female & 57 & 91.9 & & & \\
\hline Male & 5 & 8.1 & & & \\
\hline \multicolumn{6}{|l|}{ Side } \\
\hline Right & 21 & 33.9 & & & \\
\hline Left & 41 & 66.1 & & & \\
\hline \multicolumn{6}{|l|}{ Cast exchange } \\
\hline+ & 13 & 21.0 & & & \\
\hline- & 49 & 79.0 & & & \\
\hline \multicolumn{6}{|l|}{ Previous treatment (Pavlik or other braces) } \\
\hline+ & 23 & 37.1 & & & \\
\hline- & 39 & 62.9 & & & \\
\hline Acetabular head index & & & $70.5 \pm 1.4$ & 70.8 & $68.0-73.3$ \\
\hline Head coverage index & & & $14.3 \pm 0.6$ & 14.3 & 13.1-15.7 \\
\hline Sphericity & & & $0.8 \pm 0.1$ & 0.8 & $0.6-0.9$ \\
\hline Bony acetabular index & & & $37.5 \pm 3.9$ & 36.5 & $30.1-44.8$ \\
\hline Cartilage acetabular index & & & $20.3 \pm 1.2$ & 20.1 & $18.0-23.0$ \\
\hline Anterior acetabular index & & & $60.3 \pm 1.9$ & 60.0 & $57.0-64.0$ \\
\hline Posterior acetabular index & & & $64.7 \pm 1.4$ & 65.0 & $62.0-67.0$ \\
\hline Hip abduction angle & & & $58.3 \pm 4.8$ & 58.5 & $43.0-67.0$ \\
\hline Acetabular medial wall thickness (mm) & & & $7.5 \pm 0.9$ & 7.3 & 5.9-11.1 \\
\hline Acetabular index & & & $37.7 \pm 4.3$ & 37.0 & $29.0-45.0$ \\
\hline Early postoperative acetabular index & & & $29.9 \pm 3.2$ & 29.0 & $18.0-39.0$ \\
\hline Last follow-up acetabular index & & & $25.4 \pm 3.7$ & 25.0 & $16.0-34.0$ \\
\hline
\end{tabular}




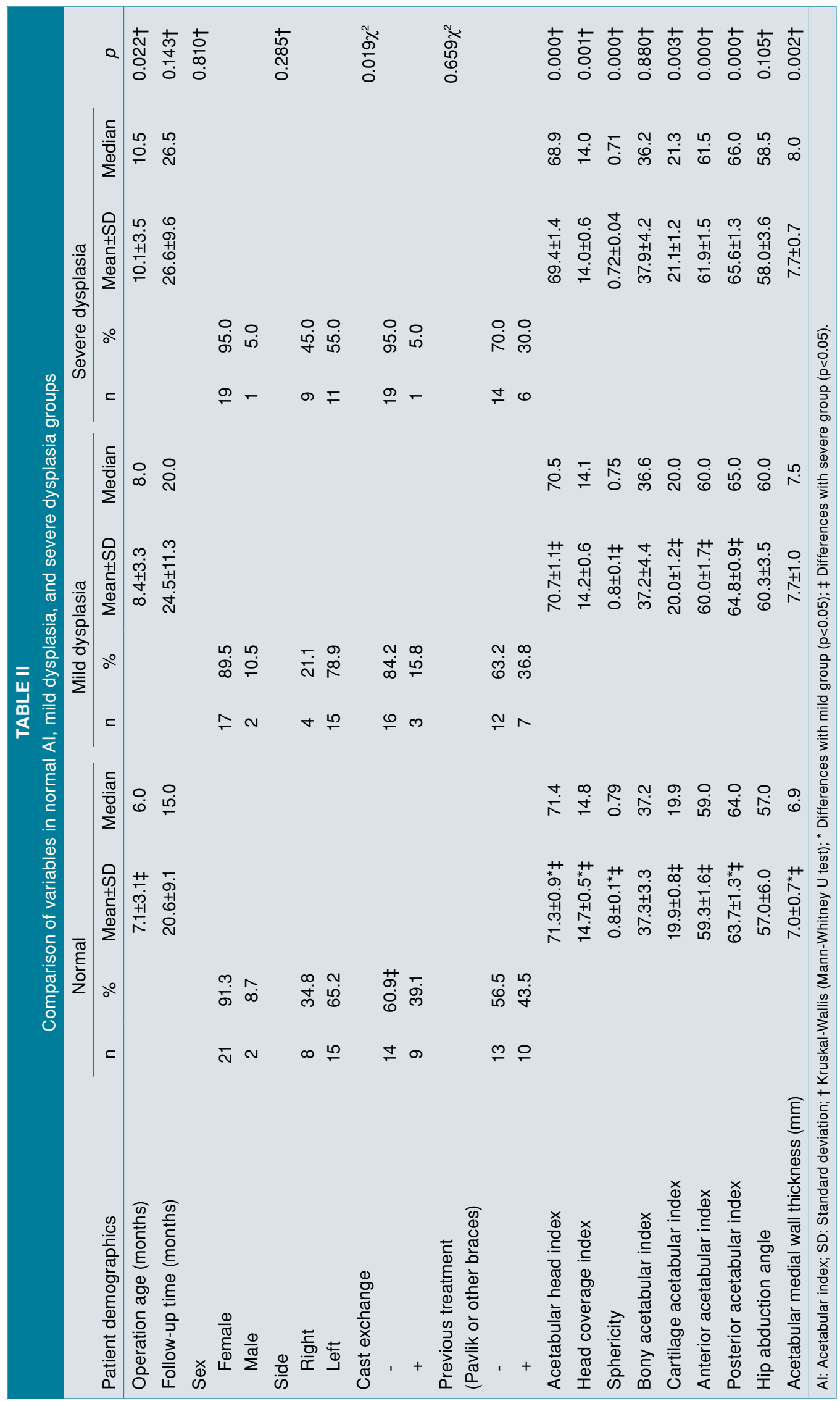




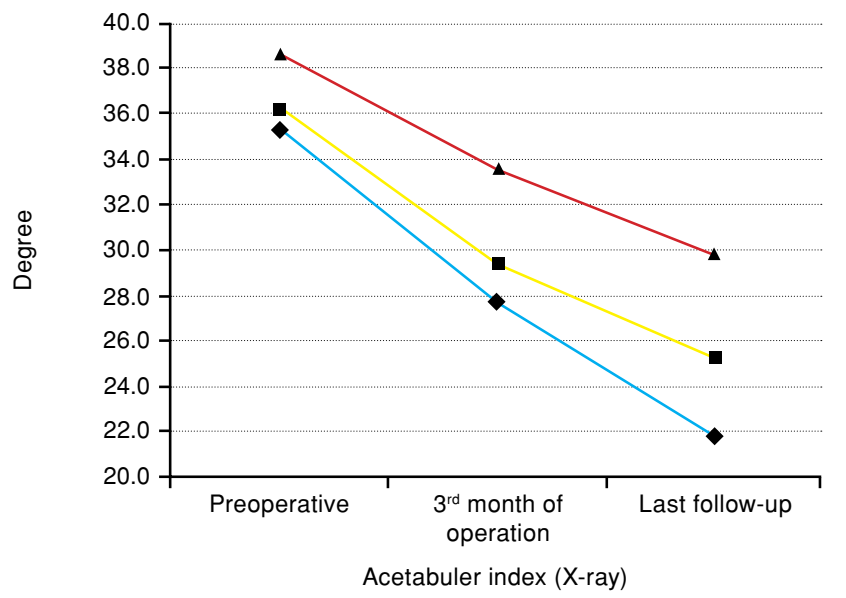

FIGURE 2. Acetabular index change from the beginning to last follow-up in the normal (blue), mild (yellow), and severe (red) dysplasia groups.

months. A cast exchange was needed in 13 of the 62 hips (21\%). Demographic characteristics of the patients and MRI-based parameters are summarized in Table I.

The AHI and sphericity scores were significantly lower in the severe dysplasia group than in the mild and normal groups $(\mathrm{p}<000.1)$. The sphericity score was significantly lower in the mild dysplasia group than in the normal group $(\mathrm{p}<000.1)$. The CAI was significantly higher in the severe dysplasia group than in the mild and normal groups $(\mathrm{p}=0.003)$. The
AAI and PAI were significantly higher in the severe dysplasia group than in the mild and normal groups $(p<0.001)$. The HCI was significantly lower in the mild and severe dysplasia groups than in the normal group ( $\mathrm{p}=0.001$ ). The AMWT was significantly higher in the mild and severe dysplasia groups than in the normal group $(\mathrm{p}=0.002)$. The results are summarized in Table II. At the time of operation, the AI was not significantly different among the three groups $(\mathrm{p}=0.88)$.

The last follow-up AI and third-month AI were significantly higher in the severe dysplasia group than in the mild dysplasia and normal groups $(\mathrm{p}<0.001)$. The last follow-up AI and third-month AI were significantly higher in the mild dysplasia group than in the normal group $(\mathrm{p}<0.001)$. Figure 2 shows the change of AI from the operation day to the last follow-up in the three groups.

The correlation between the MRI parameters of the patients and last follow-up AI is summarized in Table III. Accordingly, the operation age $(\mathrm{r}=0.250, \mathrm{p}=0.049)$, AMWT $(\mathrm{r}=0.304, \mathrm{p}=0.016)$, AAI $(\mathrm{r}=0.729, \mathrm{p}<0.001)$, PAI $(\mathrm{r}=0.590, \mathrm{p}<0.001)$, and early postoperative AI $(r=0.9, p<0.001)$ at the third month after the operation were positively correlated with the last follow-up AI. The AHI $(\mathrm{r}=-0.512, \mathrm{p}<0.001)$, sphericity $(\mathrm{r}=-0.661, \mathrm{p}<0.001)$, and HCI $(\mathrm{r}=-0.554$, $\mathrm{p}<0.001)$ were negatively correlated with the last follow-up AI. The mean AMWT was $7.5 \pm 0.9 \mathrm{~mm}$. The AMWT showed excellent intra- and inter-observer

\begin{tabular}{|c|c|c|c|c|c|}
\hline \multicolumn{6}{|c|}{ 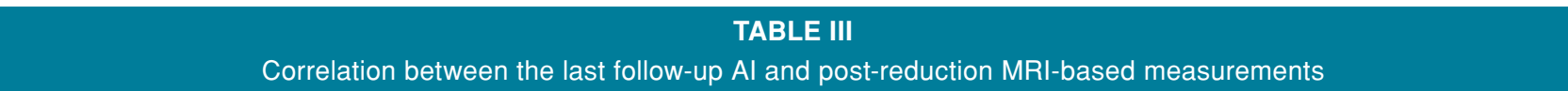 } \\
\hline & $\begin{array}{l}\text { Operation age } \\
\text { (month) }\end{array}$ & $\begin{array}{l}\text { Follow-up time } \\
\text { (month) }\end{array}$ & $\begin{array}{c}\text { Acetabular head } \\
\text { index }\end{array}$ & Sphericity & $\begin{array}{l}\text { Acetabular } \\
\text { indeks }\end{array}$ \\
\hline \multicolumn{6}{|c|}{ Last follow-up acetabular index } \\
\hline$r$ & 0.250 & -0.248 & -0.512 & -0.661 & -0.030 \\
\hline \multirow[t]{2}{*}{$p$} & 0.049 & 0.052 & 0.000 & 0.000 & 0.819 \\
\hline & $\begin{array}{l}\text { Bony acetabular } \\
\text { index }\end{array}$ & $\begin{array}{l}\text { Cartilage } \\
\text { acetabular index }\end{array}$ & $\begin{array}{l}\text { Acetabular medial } \\
\text { wall thickness }(\mathrm{mm})\end{array}$ & $\begin{array}{l}\text { Head coverage } \\
\text { index }\end{array}$ & $\begin{array}{l}\text { Hip abduction } \\
\text { angle }\end{array}$ \\
\hline \multicolumn{6}{|c|}{ Last follow-up acetabular index } \\
\hline$r$ & -0.032 & 0.462 & 0.304 & -0.554 & 0.064 \\
\hline \multirow[t]{2}{*}{$\mathrm{p}$} & 0.808 & 0.000 & 0.016 & 0.000 & 0.621 \\
\hline & $\begin{array}{l}\text { Anterior } \\
\text { acetabular index }\end{array}$ & $\begin{array}{l}\text { Posterior } \\
\text { acetabular index }\end{array}$ & $\begin{array}{l}\text { Early postoperative } \\
\text { acetabular index }\end{array}$ & & \\
\hline \multicolumn{6}{|c|}{ Last follow-up acetabular index } \\
\hline$r$ & 0.729 & 0.590 & 0.900 & & \\
\hline $\mathrm{p}$ & 0.000 & 0.000 & 0.000 & & \\
\hline
\end{tabular}


reliability: kappa, 0.976; 95\% confidence interval (CI), 0.97-0.99; p<0.001; and kappa, 0.958; 95\% CI, 0.924-0.986; $\mathrm{p}<0.001$, respectively.

\section{DISCUSSION}

The present study attempted to investigate the correlation between postoperative MRI assessment and residual $\mathrm{AI}$ in DDH patients who underwent open reduction during infancy. The main finding of this study was that the last follow-up AI was positively correlated with age at the time of operation, CAI, AAI, PAI, early postoperative AI, and medial wall thickness. The last follow-up AI was negatively correlated with AHI, HCI, and sphericity. The relationship between medial wall bone stock and acetabular dysplasia has been previously investigated in an adult population..$^{[20-22]}$ To the best of our knowledge, this is the first study to evaluate medial wall thickness in postoperative hip reduction MRI scans during infancy. We found that the medial wall thickness was significantly higher in the mild and severe dysplasia groups than in the normal group $(p=0.002)$. We hypothesized that, in a shallow acetabulum, the medial wall bone stock would be higher, and by remodeling, the medial wall would become thinner, and the acetabulum would become deeper. Therefore, we consider that shallow acetabula should have thicker medial walls. Our results confirm the hypothesis as these hips had a higher AI at the last follow-up.

Mitchell et al. ${ }^{[23]}$ evaluated MRI parameters obtained immediately after the reduction of the hip as a predictor of long-term acetabular dysplasia. They concluded that they could not predict which hips would remain dysplastic and require pelvic osteotomy based on post-reduction MRI scans. However, they analyzed only 13 hips in their study, which is a very low number to identify the relationship between MRI measurements after reduction and residual acetabular dysplasia. In our study, we included 62 hips, and the correlation between MRI parameters and acetabular dysplasia was documented. We analyzed a higher number of patients and found that the mean age of patients with severe dysplasia was significantly higher than the other normal and mild dysplasia groups $(p=0.022)$, unlike the study of Mitchell et al. ${ }^{[23]}$ We also found that there was a positive correlation between last follow-up AI and operation age $(\mathrm{p}=0.049)$. This is an expected finding of the present study, as younger children have a greater remodeling capacity. ${ }^{[23]}$ However, we still need to consider the $p$ value very close to the 0.05 .
In another study, Duffy et al. ${ }^{[15]}$ investigated 73 hip MRI scans after closed or open reduction. However, they could not find a correlation between the appearance of the bony or cartilaginous MRI scans and the acetabular morphology at the last follow-up. However, they only had a 15-month follow-up time (range, 2 to 36 months), and they suggested that a longer follow-up time was required to show a correlation. The mean follow-up time in our study was $23.7 \pm 10.1$ months, and we excluded patients with a follow-up time of less than 12 months. Our results provide valuable evidence of the correlation between patient MRI parameters and the AI at the last follow-up. Of note, we only investigated who underwent medial open reduction patients, unlike the study of Duffy et al. ${ }^{[15]}$ Open and closed reduction procedures are completely different from each other, and they should be evaluated separately. Duffy et al. ${ }^{[15]}$ reported significant differences between the normal and dysplastic acetabulum with respect to the PAI $(p<0.001)$ and AAI $(p<0.001)$. According to our results, there was a positive correlation between the PAI $(\mathrm{r}=0.590, \mathrm{p}=0.001)$, and AAI $(\mathrm{r}=0.729, \mathrm{p}=0.001)$. Even if this measurement confirms each other to predict secondary intervention, we need further longer-term studies.

The Tonnis classification system is widely used to evaluate the severity of persistent acetabular dysplasia. ${ }^{[2,25]}$ We classified patients according to the last follow-up AI in our study. The patients who needed a cast exchange had a statistically significantly ( $\mathrm{p}=0.007)$ higher AI at the last follow-up. It is difficult to explain how a cast exchange affects the AI, although it may not be clinically important. In the severe dysplasia group, the operation age was also higher. It may be related to a greater need for cast exchanges in the higher age group, as the operation age is clinically associated with severe acetabular dysplasia.

Nonetheless, this study has some limitations. First, the follow-up time was relatively short, and some of the mild or severe dysplasia patients are still being followed. Some of these patients would require a pelvic osteotomy at a later stage and some of them would have a normal AI as a result of a high capacity for remodeling. The patients need to be monitored up to at least five years of age. Second, osteonecrosis of the femoral head following treatment and intraoperative quality of reduction are the two important factors which directly affect the acetabular development and these factors were not taken into consideration in this study. Third, the sample size is relatively small, as we excluded patients due to artifacts or low-quality 
MRIs. As a result, a large number of normal children $(n=40)$ were excluded. It is not possible to determine the extent that this changes the data or conclusions. The variables should be evaluated with multivariate analyses with a higher number of patients. Finally, this was a retrospective study and further prospective studies using high-quality MRI should be designed to provide additional evidence.

In conclusion, even if we cannot predict which patient would require pelvic osteotomy in the future, we can speculate that a trend can be seen in predicting residual dysplasia in patients treated with open reduction for DDH with these MRI parameters.

\section{Declaration of conflicting interests}

The authors declared no conflicts of interest with respect to the authorship and/or publication of this article.

\section{Funding}

The authors received no financial support for the research and/or authorship of this article.

\section{REFERENCES}

1. Duman S, Camurcu Y, Sofu H, Ucpunar H, Akbulut D, Yildirim T. Arthroscopic versus open, medial approach, surgical reduction for developmental dysplasia of the hip in patients under 18 months of age. Acta Orthop 2019;90:292-6.

2. Harris IE, Dickens R, Menelaus MB. Use of the Pavlik harness for hip displacements. When to abandon treatment. Clin Orthop Relat Res 1992;281:29-33.

3. Sankar WN, Gornitzky AL, Clarke NMP, Herrera-Soto JA, Kelley SP, Matheney $\mathrm{T}$, et al. Closed reduction for developmental dysplasia of the hip: Early-term results from a prospective, multicenter cohort. J Pediatr Orthop 2019;39:111-8.

4. Ucpunar H, Mert M, Camurcu Y, Sofu H, Yildirim T, Bayhan AI. Does adductor tenotomy need during closed reduction have a prognostic value in the treatment of developmental dysplasia of the hip between 6 and 12 months of age? "Adductor tenotomy in the treatment of developmental dysplasia". Indian J Orthop 2020;54:48694.

5. Büyükkuşcu MÖ, Camurcu Y, Misir A, Gursu S, Sahin V. Previous hip surgery due to developmental dysplasia of the hip affects major complication rates but not revision rates in total hip arthroplasty. Ann Med Res 2020;27:1121.

6. Alp NB, Akdağ G, Erdoğan F. Long-term results of total hip arthroplasty in developmental dysplasia of hip patients. Jt Dis Relat Surg 2020;31:298-305.

7. Kocabiyik A, Misir A, Kizkapan TB, Yildiz KI, Kaygusuz MA, Alpay Y, et al. Changes in hip, knee, and ankle coronal alignments after total hip arthroplasty with transverse femoral shortening osteotomy for unilateral crowe type IV developmental dysplasia of the hip. J Arthroplasty 2017;32:3449-56.

8. Wedge JH, Wasylenko MJ. The natural history of congenital dislocation of the hip: A critical review. Clin Orthop Relat Res 1978;137:154-62.
9. Vaquero-Picado A, González-Morán G, Garay EG, Moraleda L. Developmental dysplasia of the hip: Update of management. EFORT Open Rev 2019;4:548-56.

10. Graf R, Mohajer M, Plattner F. Hip sonography update. Quality-management, catastrophes - tips and tricks. Med Ultrason 2013;15:299-303.

11. Harcke HT. Imaging in congenital dislocation and dysplasia of the hip. Clin Orthop Relat Res 1992;281:22-8.

12. Chin MS, Betz BW, Halanski MA. Comparison of hip reduction using magnetic resonance imaging or computed tomography in hip dysplasia. J Pediatr Orthop 2011;31:525-9.

13. Westhoff B, Wild A, Seller K, Krauspe R. Magnetic resonance imaging after reduction for congenital dislocation of the hip. Arch Orthop Trauma Surg 2003;123:289-92.

14. Druschel C, Placzek R, Selka L, Seidl T, Funk J. MRI evaluation of hip containment and congruency after closed reduction in congenital hip dislocation. Hip Int 2013;23:552-9.

15. Duffy CM, Taylor FN, Coleman L, Graham HK, Nattrass GR. Magnetic resonance imaging evaluation of surgical management in developmental dysplasia of the hip in childhood. J Pediatr Orthop 2002;22:92-100.

16. Walter SG, Bornemann R, Koob S, Ossendorff R, Placzek $R$. Closed reduction as therapeutic gold standard for treatment of congenital hip dislocation. Z Orthop Unfall 2020;158:475-80.

17. Huber H, Mainard-Simard L, Lascombes P, Renaud F, Jean-Baptiste M, Journeau P. Normal values of bony, cartilaginous, and labral coverage of the infant hip in MR imaging. J Pediatr Orthop 2014;34:674-8.

18. Jaremko JL, Wang CC, Dulai S. Reliability of indices measured on infant hip MRI at time of spica cast application for dysplasia. Hip Int 2014;24:405-16.

19. Tönnis D. Normal values of the hip joint for the evaluation of X-rays in children and adults. Clin Orthop Relat Res 1976;119:39-47.

20. Liu RY, Wang KZ, Wang CS, Dang XQ, Tong ZQ. Evaluation of medial acetabular wall bone stock in patients with developmental dysplasia of the hip using a helical computed tomography multiplanar reconstruction technique. Acta Radiol 2009;50:791-7.

21. Werner CM, Copeland CE, Ruckstuhl T, Stromberg J, Turen $\mathrm{CH}$, Bouaicha S. Relationship between Wiberg's lateral center edge angle, Lequesne's acetabular index, and medial acetabular bone stock. Skeletal Radiol 2011;40:1435-9.

22. Zengy Y, Min L, Lai OJ, Shen B, Yang J, Zhou ZK, et al. Acetabular morphological analysis in patients with high dislocated DDH using three-dimensional surface reconstruction technique. Sichuan Da Xue Xue Bao Yi Xue Ban 2015;46:296-300.

23. Mitchell PD, Chew NS, Goutos I, Healy JC, Lee JC, Evans $\mathrm{S}$, et al. The value of MRI undertaken immediately after reduction of the hip as a predictor of long-term acetabular dysplasia. J Bone Joint Surg [Br] 2007;89:948-52.

24. Cashman JP, Round J, Taylor G, Clarke NM. The natural history of developmental dysplasia of the hip after early supervised treatment in the Pavlik harness. A prospective, longitudinal follow-up. J Bone Joint Surg [Br] 2002;84:418-25.

25. Gwynne Jones DP, Vane AG, Coulter G, Herbison P, Dunbar JD. Ultrasound measurements in the management of unstable hips treated with the Pavlik harness: Reliability and correlation with outcome. J Pediatr Orthop 2006;26:818-22. 